\title{
HABITAÇÃO SOCIAL EM VAZIOS URBANOS NA MICRORREGIÃO 07 EM PRESIDENTE PRUDENTE - SP
}

\author{
Mayara Pissuti Albano, Thais Cabrera Leite, Yeda Ruiz Maria
}

Universidade do Oeste Paulista - UNOESTE, curso de Arquitetura e Urbanismo, Presidente Prudente, SP. E-mail: thaiscabrera95@gmail.com

\begin{abstract}
RESUMO
No Brasil a carência de moradia adequada, entendida não apenas como um mero abrigo, mas também como um conjunto de elementos ligados ao saneamento básico, serviços urbanos, educação e saúde constitui um grande problema. Atualmente, áreas urbanas desfavorecidas têm uma presença marcante na paisagem urbana brasileira. A moradia, que pode ser entendida como uma necessidade básica, mas os acessos às áreas estruturadas são restritos, o que acaba levando essa população a morar em loteamentos periféricos e na irregularidade. Este trabalho possui o intuito de apontar um terreno que se encontra vazio para implantação de um conjunto de habitação popular na Microrregião 07 da cidade de Presidente Prudente - SP, bem como propor diretrizes projetuais para o referido conjunto. A importância desse estudo é justificada pelo crescimento constante e descontínuo da malha urbana da referida cidade, sem gestão e planejamento adequado. A metodologia será baseada em levantamentos bibliográficos, documentais e de campo.
\end{abstract}

Palavras-chave: Áreas urbanas. Vazios urbanos. Habitação social. Microrregião 07. Presidente Prudente - SP

SOCIAL HOUSING IN URBAN EMPTINESSES ON MICROREGION 07 OF PRESIDENTE PRUDENTE - SP

\section{ABSTRACT}

The lack of housing in Brazil, understood not only as a shelter, but also as a set of elements related to basic sanitation, urban services, education and health is a big problem. Currently, disadvantaged urban areas have a marked presence in the Brazilian urban landscape. Housing, which can be understood as a basic need, but the accesses to the structured areas are restricted, which ends up leading this population to live in peripheral subdivisions and irregularity. This work intends to propose a set of social housing interest in urban emptinesses on Microregion 07 of the city of Presidente Prudente - SP, as well as proposing projetcts guidelines for the whole. The importance of this study is justified by the constant and discontinuous growth of the city's urban network, without proper management and planning. The methodology will be based on bibliographical, documentary and field surveys.

Keywords: Urban área. Urban emptinesses. Social Housing. Microregion 07. Presidente Prudente SP.

\section{INTRODUÇÃO}

A dificuldade de acesso à terra urbana e à habitação por meios regulares induz a população de baixa renda a se abrigar em áreas públicas ou particulares abandonadas, em áreas alagadiças, nas encostas de morros, embaixo de pontes e viadutos. Embora isto esteja marcado pela irregularidade, ilegalidade e pela clandestinidade, pode-se dizer que ela conta com certa cumplicidade do poder público, perante sua incapacidade de gerar moradias adequadas para essa população (LORENZETTI, 2001). 
Ao longo do tempo, os conjuntos habitacionais inseridos por políticas habitacionais geralmente se localizam nas periferias da cidade, locais sem equipamentos urbanos adequados e comércio, com infraestrutura precária, ocasionando a exclusão sócio espacial.

Em Presidente Prudente é comum vivenciar a implantação de moradias, apoiadas em políticas públicas, porém, na maioria das vezes fora da malha urbana consolidada (ALBANO, 2013), ao invés de proporcionar a renovação dos vazios urbanos das áreas centrais ou em locais de infraestrutura adequada. Por consequência, os conjuntos habitacionais de baixa renda são construídos em loteamentos periféricos, provocando o crescimento da malha urbana, contribuindo para a formação de vazios urbanos (MARICATO, 2008).

Esse fato gera segregação e inúmeros problemas à cidade que poderia logo ser resolvido ao receber novos usos, ajudando a não proporcionar um crescimento da malha urbana sem a devida gestão ou planejamento. Nesse processo, ao se abordar a temática "vazios urbanos" logo é citado sobre a especulação imobiliária, porém, esses espaços ociosos não se reduzem apenas a este processo, existindo outras características para defini-los como aqueles que resultaram da ação do Estado, na instalação de conjuntos habitacionais, aquelas áreas negociadas recentemente, que ainda não foram alvo de loteamento e construção etc. (MARICATO, 2008; NASCIMENTO, 2014).

Assim, discute-se a necessidade de estudar a situação da cidade de Presidente Prudente em relação a esse crescimento urbano desenfreado, visto que a mesma apresenta áreas significativas conformadas como vazios urbanos inseridos na malha urbana consolidada. Do mesmo modo, Maricato (2008) afirma que é importante debater a proposta de uma ocupação desses territórios com habitações sociais destinadas a população de baixa renda.

Deste modo, justifica-se a relevância do estudo pela necessidade de discutir a atual situação da Microrregião $07^{1}$ de Presidente Prudente - SP em relação ao crescimento constante e descontínuo da malha urbana, sem gestão e planejamento adequado. É de suma importância a discussão em âmbito social para uma proposta de ocupação destas áreas inicialmente com habitações destinadas a classe baixa da população.

O objetivo geral deste trabalho é a escolha e análise de um terreno conformado como vazio urbano inserido na Microrregião 07 para a inserção de um conjunto de habitação social, bem como estabelecer diretrizes para o projeto arquitetônico do mesmo.

\section{METODOLOGIA}

O presente trabalho tem como metodologia de pesquisa, a análise qualitativa, que foi desenvolvida em etapas como: revisão bibliográfica, com levantamento de autores que trabalham a história das políticas habitacionais, a formação de vazios urbanos e que discutam o programa Minha Casa Minha Vida e dos projetos que servirão de referência projetual.

Pesquisas documentais como mapas e documentos cadastrais referentes à Microrregião 07 de Presidente Prudente, para a escolha e respectivas análises do lote em estudo, que também precisaram dos subsídios gerados através dos levantamentos físicos territoriais in loco, como levantamento de uso e ocupação do solo urbano do entorno, medições para auferir a área do lote, levantamento do gabarito de altura das edificações vizinhas, entre outras análises que colaboraram para a elaboração das diretrizes de projeto.

Os levantamentos físicos territoriais geraram peças gráficas (mapas, plantas, cortes e elevações) que forma desenvolvidas com o auxílio dos softweres AutoCad e Spring.

\footnotetext{
${ }^{1}$ Presidente Prudente foi dividida em 18 Microrregiões Administrativas pela prefeitura municipal, à fim de facilitar ações de planejamento urbano.

Colloquium Socialis, Presidente Prudente, v. 01, n. Especial 2, Jul/Dez, 2017, p.715-721. DOI: 10.5747/cs.2017.v01.nesp2.s0218
} 


\section{BREVE HISTÓRIA DA HABITAÇÃO SOCIAL}

Mesmo que as habitações precárias sempre tivessem presentes no Brasil, elas só passaram a ser um "problema" às autoridades em meados da década de 1880 , quando começou a surgir atividades urbanas ligadas ao complexo cafeeiro, trazendo para a cidade uma concentração de trabalhadores mal alojados em cortiços e casas de cômodos que representavam uma grave ameaça à saúde pública, já que, até a década de 1930, a forma dominante de morar era a casa de aluguel, e seus proprietários economizavam ao máximo nas construções a fim de aumentar os lucros (BONDUKI, 2004).

A partir da Era Vargas (1930-1945), o Estado começa a desenvolver políticas de modernização do Brasil e o tema habitação social estava com uma força jamais vista. $O$ estado intervém no setor habitacional propondo a obtenção da casa própria por meio de políticas públicas, barateando o custo da produção e dando maior facilidade para o trabalhador construir a sua moradia (ALBANO, 2013; HONDA, 2011). Dentre as ações do governo para o setor estão o "congelamento dos aluguéis, produção em massa de moradias por intermédio dos $I A P^{2} s$ e criação da Fundação da Casa Popular" (BONDUKI, 2004, p. 209).

Em 31 de março de 1964, ocorre o golpe militar e todas as políticas habitacionais vigentes são extintas. Em alguns meses, uma nova política habitacional é iniciada, a Lei № 4.380 institui o Plano Nacional de Habitação, criando o Sistema Financeiro de Habitação (SFH), o Banco Nacional da Habitação (BNH) e o Serviço Federal de Habitação e Urbanismo (SERFHAU). Dentre as principais características de atuação deste período estão a produção em massa de unidades habitacionais em terrenos distantes e desconectados da malha urbana, gerando enormes vazios urbanos (BONDUKI, 2004).

Depois de diversos problemas durante o regime militar, 22 anos de atuação, o BNH é extinto, deixando inda um grande déficit habitacional. Uma parcela do espaço urbano do país poderia ter uma excelente qualidade urbana e ambiental se as intervenções, financiadas pelo Estado, tivessem sido realizadas de forma diferente (BONDUKI, 2004).

Durante o período de redemocratização, existiram diversos programas habitacionais com representatividade menor no cenário das políticas habitacionais, com destaque para o Programa de Arrendamento Residencial - PAR, criado durante o governo Fernando Henrique Cardos na década de 1990 (ALBANO, 2013).

Luís Inácio Lula da Silva toma posse como Presidente da República em 2003 e cria o Ministério das Cidades (MCidades), incorporando as atividades relacionadas ao setor habitacional. O Programa Minha Casa Minha Vida (PMCMV), criado em 2009 e vigente até os dias atuais, cria possibilidades de aquisição ou produção de moradias para a população com renda de até dez salários mínimos, tendo recursos da União e do FGTS e tendo como responsável pelo financiamento a CAIXA. O programa possui uma tabela de especificações do mobiliário a ser inserido em cada ambiente, além dos materiais a serem utilizado. As moradias devem estar inseridas na malha urbana, com adequada infraestrutura. (HONDA, 2011).

Pela origem, o Minha Casa Minha Vida é um programa econômico. O mesmo foi concebido pelos ministérios Civil e da Fazenda, em diálogo com o setor imobiliário e da construção civil, como uma forma de enfrentamento da chamada "crise dos subprimes americanos", que provocou a quebra de bancos e impactos a economia financeirizada mundial (AMORE, 2015).

Destaca-se que o PMCMV é dividido, até então, em duas etapas, sendo que a primeira vigorou de 2009 a 2011, no governo de Luiz Inácio Lula da Silva e a segunda etapa de 2013 a 2014 no governo de Dilma Rousseff. A diferença entre ambos se encontra na ampliação da faixa de renda das famílias, com o intuito de expandir o número de beneficiados, bem como a não

\footnotetext{
${ }^{2}$ Institutos de Aposentadoria e Pensão - IAPs foram os órgãos responsáveis por produzir, alugar e financiar moradias populares na Era Vargas, com recursos dos fundos de pensão.

Colloquium Socialis, Presidente Prudente, v. 01, n. Especial 2, Jul/Dez, 2017, p.715-721. DOI: 10.5747/cs.2017.v01.nesp2.s0218
} 
autorização de venda dos imóveis de famílias de menor renda antes da quitação da dívida, reforma de habitações rurais para famílias de baixa renda e melhoria das casas construídas (MAROSO, 2017).

O seu maior foco, segundo o próprio governo, está na população de baixa renda. As faixas 1 e 1,5 são as que mais contam com subsídio da União, podendo chegar a até $90 \%$ do valor do imóvel. O Fundo de Arrendamento Residencial (FAR) é utilizado em operações realizadas diretamente pelas prefeituras, pelas construtoras ou em parceria entre estes agentes. A construtora pode apresentar para o órgão financiador a operação completa, com terreno, projetos e licenciamento, orçamentos e cronogramas. A prefeitura pode disponibilizar terra e promover "chamamentos" para que construtoras apresentem o pacote completo da produção. (AMORE, 2015).

A política habitacional contemporânea, da forma em que vem sendo executada, não é diferente das políticas anteriores, afinal, permanece com a mesma lógica de assentamento, distanciando as populações pobres das áreas urbanas consolidadas, onde há condições de infraestrutura física e social. Porém, apesar de seus diversos problemas, o PMCMV conseguiu contribuir positivamente para o cenário habitacional nacional, ao atender famílias com renda zero, dispondo de aporto financeiro ou fundo perdido. Ou seja, apenas uma pequena porcentagem da verba destinada às moradias populares retomará aos cofres públicos. Da mesma maneira, o programa conseguiu responder ao déficit habitacional (MAROSO, 2017).

Por ser a política habitacional contemporânea, as diretrizes projetuais propostas no presente trabalho, seguirão as proposições do Programa Minha Casa Minha Vida.

\section{VAZIOS URBANOS}

Os vazios urbanos têm sido cada vez mais presentes no espaço urbano, surgindo como mais um resultado a ser estudado, mas ainda não explorado o suficiente. Isso se explica pelo fato do vazio ser fenômeno recente na história das cidades brasileiras, marcadamente a partir da década de 1960, como uma presença generalizada em cidades de certo porte. A partir daí os vazios passaram a ganhar dimensão e evidência, sendo intencionalmente produzidos como estratégia tanto pública, quanto privada, de estimular o negócio com a terra urbana. (NASCIMENTO, 2014, p. 27)

A expressão "vazio urbano" abrange diversos significados. Dittmar (2006) afirma que há o consenso de vários autores que consideram o vazio urbano como áreas "construídas", não no sentido físico, mas no que se refere ao trabalho social em seu entorno. Segundo Villaça (apud CLEMENTE, 2011) o vazio urbano é uma grande extensão de área equipada ou semiequipada, com quantidade de glebas ou lotes vagos. Para Clemente (2011), "vazio urbano" apresenta diversas definições, em conjunturas diversas e com objetivos distintos.

Clemente (2011) afirma que o vazio urbano é o espaço que não foi concebido como espaço livre público, estando este sem ocupação e/ou sem uso o que gera uma conotação negativa dentro do meio intraurbano, podendo receber alterações futuramente, mas lotes sem edificações (nunca ocupados ou fruto de demolições) como edificações sem utilizações no momento pode ser considerada vazios urbanos, desde que estejam em áreas urbanizadas.

\section{ESCOLHA DA ÁREA E DIRETRIZES PROJETUAIS}

A área analisada encontra-se na Microrregião 07 - MR 07 do município de Presidente Prudente - SP e está a sudoeste da cidade e engloba 24 bairros, todos de alta e média renda. Após um levantamento físico e mapeamento vetorizado, foi possível identificar pequenas irregularidades na área, incluindo vazios urbanos.

A MR 07 está em constante crescimento, aumentando cada vez mais a demanda por moradias. O Jardim Petrópolis, bairro em que o terreno está inserido, é um bairro de média e alta 
renda e possui inúmeros vazios urbanos que não estão cumprindo sua função social. Sendo assim, um projeto de habitação social nessa área daria um novo uso a este vazio, contestando a segregação urbana existente na cidade.

O terreno escolhido para o projeto possui $4.863,60 \mathrm{~m}^{2}$ e está dentro da malha urbana consolidada, a sudoeste do centro da cidade (Figura 1).

Figura 1 - Localização do terreno

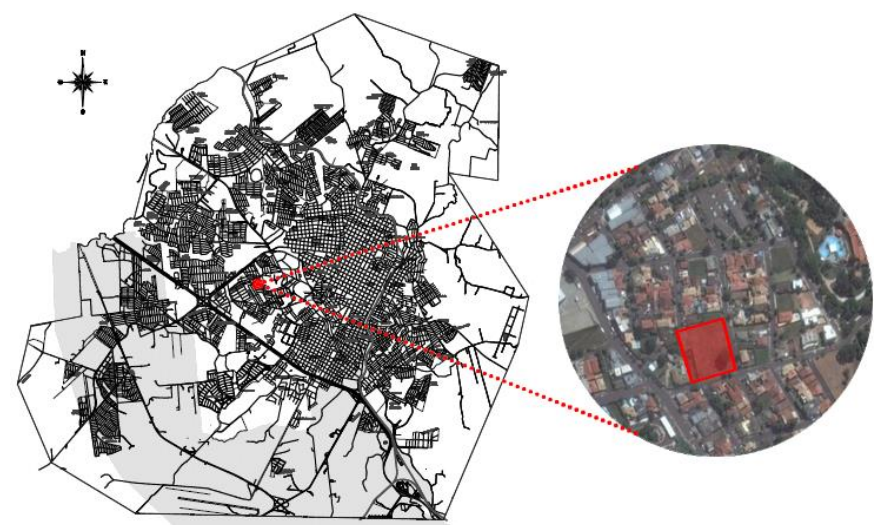

Fonte: Prefeitura Municipal de Presidente Prudente; Google Earth. Modificação: autores (2017).

O Jardim Petrópolis, bairro onde se localiza o terreno escolhido, apresenta edificações residenciais com predominância de edificações com um e dois pavimentos, com raros casos com três pavimentos.

O terreno escolhido sempre esteve vazio, sem nenhum tipo de uso durante anos. Atualmente seu estado continua o mesmo, sem edificações e sem manutenção da vegetação, dificultando a visão completa do espaço (Figura 2). Seu entorno conta com muitos vazios além de ter algumas edificações para sublocação, no entanto apresenta grande quantidade comercios e serviços, contando com bares, lojas e clínicas médicas, e a presença de uma edificação institucional, o prédio da Justiça Federal.

Figura 2 - Terreno escolhido
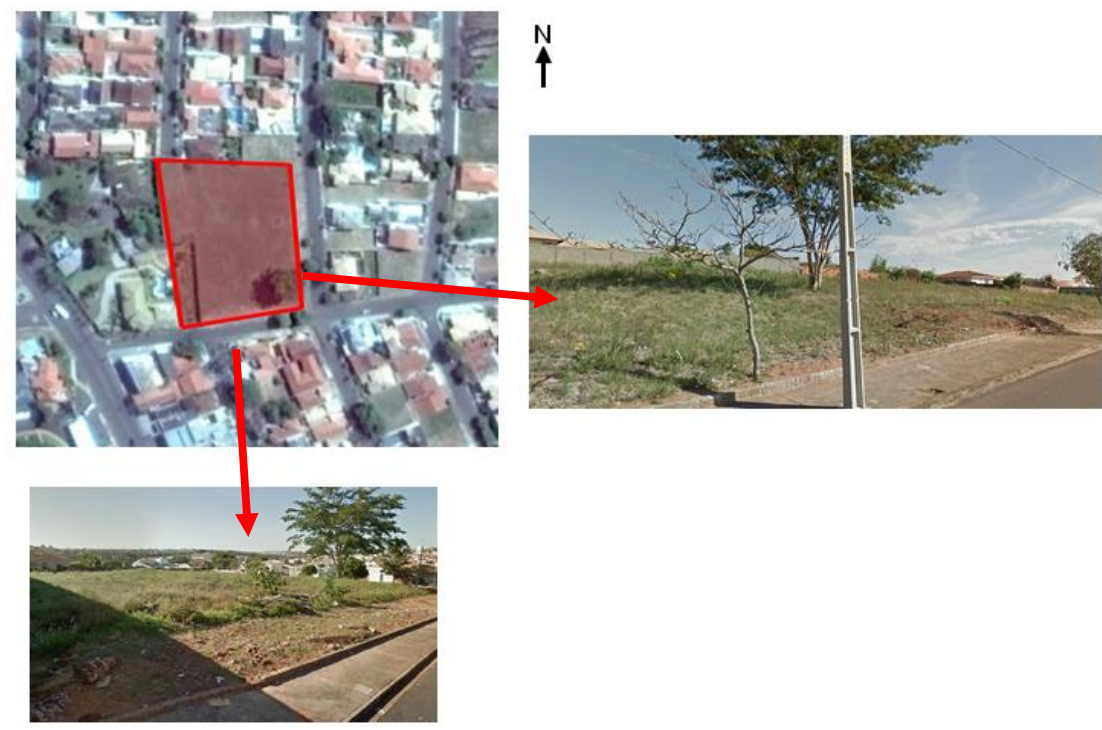

Fonte: Google Earth. Fotos e Modificação: autores (2017).

Para este projeto toma-se como diretrizes projetuais as pré-definidas pelo programa Minha Casa, Minha Vida, discorridas através da Portara no 168 de abril de 2013. 
Dentre tais diretrizes vale ressaltar que o programa propõe a promoção da melhoria da qualidade de vida das famílias beneficiadas; a provisão habitacional em consonância com os planos diretores municipais; a criação de novos postos de trabalho diretos e indiretos; a promoção de condições de acessibilidade a todas as áreas públicas e de uso comum, além da disponibilidade de unidades adaptáveis ao uso por pessoas com deficiência; o atendimento às diretrizes do Programa Brasileiro da Qualidade e Produtividade - PBQP-H; a execução de trabalhos sociais, entendido como um conjunto de ações inclusivas, de caráter socioeducativo, voltadas para o fortalecimento da autonomia das famílias, sua inclusão produtiva e a participação cidadã; e a reserva de, no mínimo, 3\% das unidades habitacionais para atendimento aos idosos no processo de seleção dos beneficiários, regulado por normativo específico.

\section{CONCLUSÃO}

Após pesquisas bibliográficas, documentais e de campo realizadas, pode-se dizer que conjunto habitacional contribuirá para a demanda habitacional existente no município. Pensar na habitação social inserida em um vazio urbano, local onde há oferta de infraestrutura, é pensar em uma cidade mais inclusiva e que proporcione uma melhor qualidade de vida para a população de baixa renda que, historicamente, é contemplada com conjuntos implantados nas margens da cidade.

\section{REFERÊNCIAS BIBLIOGRÁFICAS}

ALBANO, Mayara P. A importância do Planejamento urbano ambiental - a habitação social e a expansão urbana de Presidente Prudente - SP. Dissertação (Mestrado Meio Ambiente e Desenvolvimento Regional) - UNOESTE, Presidente Prudente, 2013.

AMORE, Caio S. Minha Casa... e a Cidade? 1 ed. Rio de Janeiro: Letra Capital, 2015. Disponível em: <http://www.observatoriodasmetropoles.net/images/abook_file/mcmv_nacional2015.pdf>.

Acesso: 25 abr. 2017

BONDUKI, N. Origens da Habitação Social no Brasil: arquitetura moderna, lei do inquilinato e difusão da casa própria. 6.ed. São Paulo: Estação Liberdade, 2004.

CLEMENTE, Juliana C. Vazio urbano ou subutilizado? Entre conceitos e classificações. Cadernos de pós-graduação em arquitetura e urbanismo. ISSN 1809-4120, 2011. Disponível em: < http://www.mackenzie.br/dhtm/seer/index.php/cpgau/view/Clemente.2011.2>. Acesso em: 8 fev / 2017.

HONDA, Sibila C.A.L. Habitação de baixa renda como produto de capital: o Programa de Arrendamento Residencial (PAR) em Presidente Prudente. Tese (Doutorado) - Faculdade de Arquitetura e Urbanismo, Universidade Presbiteriana Mackenzie, São Paulo, 2011.

LORENZETTI, M. A questão habitacional no Brasil. Consultoria Legislativa da Câmara dos Deputados, 2001. Disponível em: <http://bd.camara.gov.br/bd/handle/bdcamara/1469>. Acesso em: $8 \mathrm{fev} / 2017$.

MARICATO, E. Por um Novo Enfoque Teórico na Pesquisa Sobre Habitação. Cadernos Metrópole. CIDADE, v. 10, n. 21, p. 33-52. 2009 
MAROSO, Caio B. HABITAÇÃO E CIDADE: Gestão Territorial, Dispersão Urbana e o Programa Minha Casa, Minha Vida. $O$ caso dos Conjunto Habitacionais Jaguariúna I e II. Jaguariúna, São Paulo. Dissertação (Mestrado) - Pontífica Universidade Católica de Campinas, Campinas, 2017

NASCIMENTO, A.S. No vazio caberiam casas, parques, fábricas... caberia muita cidade. 2014. Dissertação (Mestrado) - Universidade Estadual Paulista, Faculdade de Ciência e Tecnologia.

SILVA, H.M.B. (Coord.); SíGOLO, L.M. Oportunidades e limites para a produção de habitação social no centro de São Paulo. Relatório de pesquisa. São Paulo: Lincoln Institute of Land Policy, 2007. 